\title{
A Special Peripheral Component Interconnect Express Card for Video Surveillance Systems in Alarm Applications
}

\begin{abstract}
Many companies use the Video Surveillance Systems (VSS) application for security applications. However, this system is usually designed as an external independent device and the security person is forced to use it locally with limited control. The aim of this paper is to design the extended Peripheral Component Interconnect Express (PCI-E) card for the VSS application for extensive companies. The card has several independent Ethernet terminals where IP cameras using Power over Ethernet (PoE) can be connected. This solution is much more cost-effective and easy to use solution than traditional Digital Video Recorder (DVR). Designed solutions guarantee flawless and reliable video signal transmission for security applications.
\end{abstract}

Streszczenie. Wiele firm używa aplikacji Video Surveillance Systems (VSS) do zastosowań związanych z bezpieczeństwem. Jednak system ten jest zwykle projektowany jako niezależne urządzenie zewnętrzne i obiekt ochrony jest zmuszony do używania go lokalnie z ograniczoną kontrolą. Celem artykułu jest zaprojektowanie rozszerzonej karty Peripheral Component Interconnect Express (PCI-E) do aplikacji VSS dla dużych firm. Karta posiada kilka niezależnych terminali Ethernet, do których można podłączyć kamery IP wykorzystujące technologię Power over Ethernet (PoE). To rozwiązanie jest znacznie tańsze $i$ łatwiejsze w użyciu niż tradycyjny cyfrowy rejestrator wideo (DVR). Zaprojektowane rozwiązania gwarantują bezbłędną $i$ niezawodną transmisję sygnału wideo w zastosowaniach związanych z bezpieczeństwem.(Specjalna karta Express Card Interconnect do urządzeń peryferyjnych do systemów nadzoru wideo w zastosowaniach alarmowych)

Keywords: Ethernet; IP Camera; Peripheral Component Interconnect - Express; Video Surveillance Systems.

Słowa kluczowe:system nadzoru video, karta Express Card Interconnect

\section{Introduction}

Nowadays, the Intruder Alarm System is spreading to all locations despite the type or place of the environment. It is a part of the technical security where people or big companies want to protect the property effectively. Mentioned technical security is done by the electronic components without any person involved which is much more cost-effective than physical protection. The author [1] mentioned that when a person stares at a screen for more than 20 minutes, his attention drops by $30 \%$; and for periods over an hour, the drop can reach up to $70 \%$. However, this type of monitoring is still widely used in large scale areas where are controlled several video outputs at once.

Every IAS should be connected to the local Alarm Receiving Center (ARC) where the alarm message can be received and evaluated. [2] The ARC has armed forces that can be deployed to the protected building. However, the person who is working in the ARC has only limited information about the alarm message. According to this problem, modern IAS has the camera system inside of the building and when the alarm is triggered, the person can easily see the current situation in real-time. $[3,4]$ The same system is used in the large scale building areas where one person should monitor several cameras at once. [5]

The most used types of cameras for the IAS are connected via the Ethernet connection where the computer or private network system is already constructed and used without any additional expenses. According to the author [6], the best way how to connect security cameras for live monitoring by the person is the direct connection. One of the most used monitoring devices of the camera system is the Personal Computer (PC) where can be installed program for the managing and setting of the system in the user-friendly interface. [7] However, the bottleneck of the concept is in the mainboard of the PC where only one Ethernet connector for the computer network is placed. There are some situations where one Ethernet port on the motherboard has not enough capacity and the live video from connected cameras starts to jamming. This problem can be solved by using more Ethernet ports by adding several extension Ethernet cards to the motherboard. [8] According to this problem, the main goal of this article is to design the special extension card with Ethernet ports which can be connected to the motherboard using the PCI-E slot.

\section{Peripheral Component Interconnect Express}

The Peripheral Component Interconnect Express (PClE) is a high-speed serial computer expansion bus standard, which has characteristics of high speed, low power, and high protocol efficiency. [9] This standard is widely used as a standard $\mathrm{I} / \mathrm{O}$ interface for connecting processors and $\mathrm{I} / \mathrm{O}$ system devices. High speed, low power, and high efficiency are the salient properties of the $\mathrm{PCl}-\mathrm{E}$; because of additional properties $\mathrm{PCl}-\mathrm{E}$ is considered as good alternatives to the existing network structures. [10]

It also uses a bus topology to enable communication between other devices on the bus, and it supports multiple lanes of $1 \mathrm{x}, 2 \mathrm{x}, 4 \mathrm{x}, 8 \mathrm{x}$ and $16 \mathrm{x}$ per link. Data rates are 2 $\mathrm{Gb} / \mathrm{s}$ per lane in $\mathrm{PCl}-\mathrm{E}$ Gen $1,4 \mathrm{~Gb} / \mathrm{s}$ per lane in $\mathrm{PCl}-\mathrm{E}$ Gen 2 and $8 \mathrm{~Gb} / \mathrm{s}$ in Gen3. [11] Every PCl-E slot has a switch which is a collection of logically connected $\mathrm{PCl}$ to $\mathrm{PCl}$ bridges. $\mathrm{PCl}-\mathrm{E}$ is one example of the general trend toward replacing parallel buses with serial interconnects like Universal Serial Bus (USB). PCl Express is a serial connection that operates more like a network than a bus. Instead of one bus that handles data from multiple sources, $\mathrm{PCl}-\mathrm{E}$ has a switch that controls several point-to-point serial connections.

The maximal dimension of the PCl-E card is $120 \times 320$ $\mathrm{cm}$ by the standard which must be used by the manufactures of the PC cases where the extension card can be placed. Every card must have the holes for the mounting screws which hold the card in place. [12] The final design of the card must respect the mentioned dimensions and other requirements.

\section{Video Surveillance Systems in Alarm Applications}

Video Surveillance Systems (VSS) have been gradually turning to be a casual part of the standard acquisition in case of household security or other small-scale alarm application. As cameras, recorders, management systems are becoming cheaper and more affordable for wide society the definition of new requirements for communication interface clear operation is demanded. Moreover, the simplification of whole communication and the VSS 
management process creates a new challenge. Typical VSS architecture is based on the security assessment of the object, nonetheless, these systems could be divided into several categories, at least for purposes of this research paper. [13]

Core components of the VSS are usually cameras, recording devices represented by network video recorder (NVR) or recording server on the image acquisition side and client station which mediates user interface for system management and purposes of its direct operation.

The complexity of these systems presented above is relatively high when the application should be small-scale VSS, for example, 4 cameras home security system. The utilization of VNR with the integrated PoE switch is the simplest possible way how to build up VSS nowadays. [14] However, there is even less complex architecture then the ones we introduced before. An all-in-one solution based on the $\mathrm{PC}$, which will take the role of recording server, management server, media streaming server, client and even PoE switch could be constructed when the designed $\mathrm{PCl}$-Express Ethernet card will be equipped and will fulfill all necessary requirements for VSS operation. [15] The following figure represents the typical architecture of VSS based on NVR supported by PoE Switch on the other hand system based on a dedicated HW unit with network interface realized through separated PoE injectors is visualized on the following figure as well.
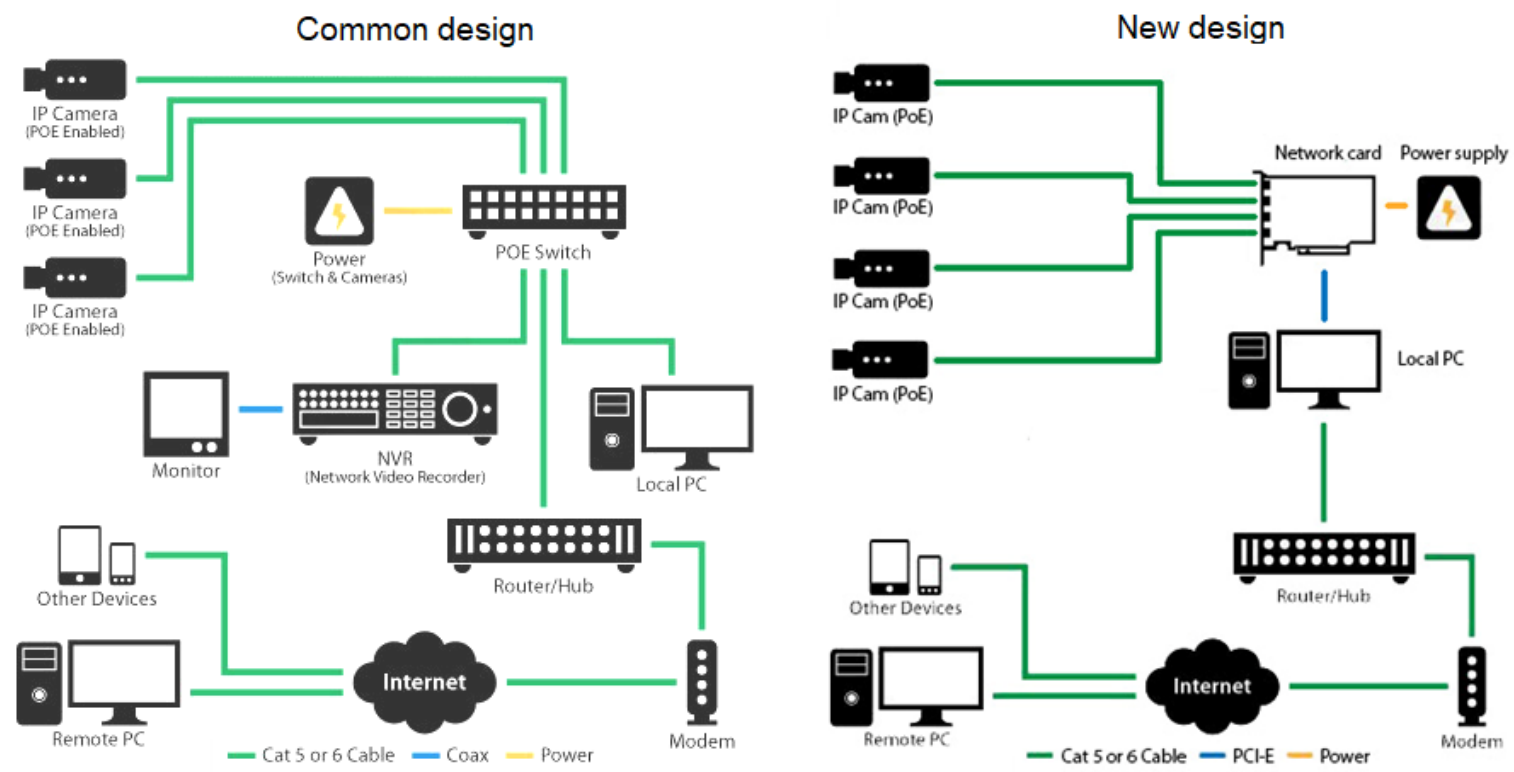

Fig.1. Architecture of the typical and new VSS design

As a multisensory, pan tilt zoom (PTZ) and panoramic cameras becoming a new standard within VSS, the demand for sufficient bandwidth and amount of power via PoE is expected. The original IEEE 802.3af-2003 PoE standard provides up to $15.4 \mathrm{~W}$ of DC power (minimum $44 \mathrm{~V} \mathrm{DC}$ and $350 \mathrm{~mA}$ ) to each device. Only $12.95 \mathrm{~W}$ is assumed to be available at the powered device as some power dissipates in the cable. The updated IEEE 802.3at-2009 PoE standard also known as PoE+ or PoE plus, provides up to $25.5 \mathrm{~W}$ of power. For powering PTZ or multi-sensor cameras, much higher power is required. Some PTZ cameras are rated at $60 \mathrm{~W}$ and some manufacturers rate them as "Hi-PoE". [16] $\mathrm{Hi}-\mathrm{PoE}$ is still not ratified by IEEE Moreover programmable relay inputs and outputs, and additional standards are required however these are defined in the following chapter.

\section{The Requirements for the VSS}

The outcome of this article is a design of the Ethernet card which must accomplish some requirements. These requirements are consulted with the external company and it should fulfil the requirements of all potential demands of VSS applications. Characterization of major Ethernet parameters related to VSS operation are the following:

- 10/100/100BASE-TX ports,

- IEEE802.3/802.3u/802.3ab,

- integrated Ethernet MAC and PHY,

- flexible address filtering modes,

- unicast/multicast modes,
- full-duplex flow control, ARP and NS offload,

- integrated Ethernet PHY,

- $\quad$ support of IEEE 802.1q VLAN tagging and more,

- PoE, PoE+ and High PoE standards on each port,

- $2 x$ Serial ATA connectors with the revision 2.6,

- $2 x \mathrm{PCl}$ Express (PCIE) 6pin power connector.

All listed requirements should be fulfilled and explained in the following chapter where schematics and explanations are listed. The whole system must be placed on a single PCB without any additional devices.

\section{The Used Components for The System}

All individual components are placed on the doublesided PCB where components are placed on the top of the board. The PCB has four layers in total due to the high level of integration. All parts of the system are connected together using different interfaces due to reliable communication. The connection between all parts is shown in the form of the block diagram in the following figure.

\section{The Ethernet circuit with LAN7430}

The LAN7430 is a highly integrated PCIE to Gigabit Ethernet controller with advanced power management features, that provides a high performance and costeffective $\mathrm{PCl}-\mathrm{E} /$ Ethernet bridging solution for automotive and industrial applications. The chip has 1 line at 2.5GT/s for chip-to-chip and card-to-card connectivity across a 
combination of printed circuit boards, connectors, backplane wirings, and cables. The LAN7430 has an integrated 10/100/1000 Ethernet PHY port with IEEE 802.3az and 10BASE-Te support, while the LAN7431 supports either a RGMII (v1.3 and v2.0) or a MII MAC port for direct connectivity to transceivers, such as 100BASE-T1 or HDBaseT.

The PHY Ethernet connection needs Ethernet Magnetic Transformers (EMT) which can transform the signals from the LAN7430 to the physical link of the Ethernet interface.
These transformers offer high isolation for robust applications, it provides safety isolation of up to $6 \mathrm{kV}$ which is ideal for technical applications. The EMT can be placed on the PCB or it can be integrated into the RJ-45 connector which saves a lot of space on the board. Due to the electromagnetic interference, the simple filters are added to the design according to the datasheet. The part of the schema can be found in the following figure.
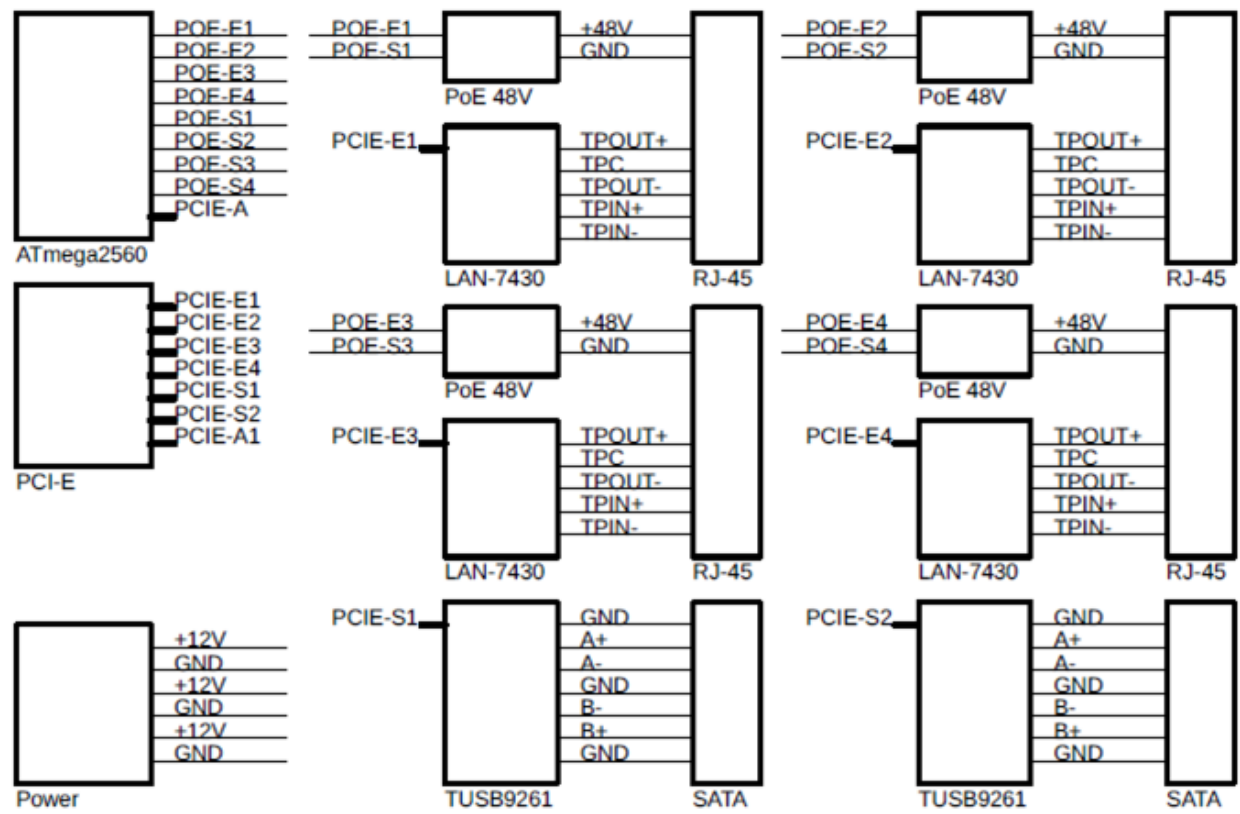

Fig.2. The block diagram of the VSS design
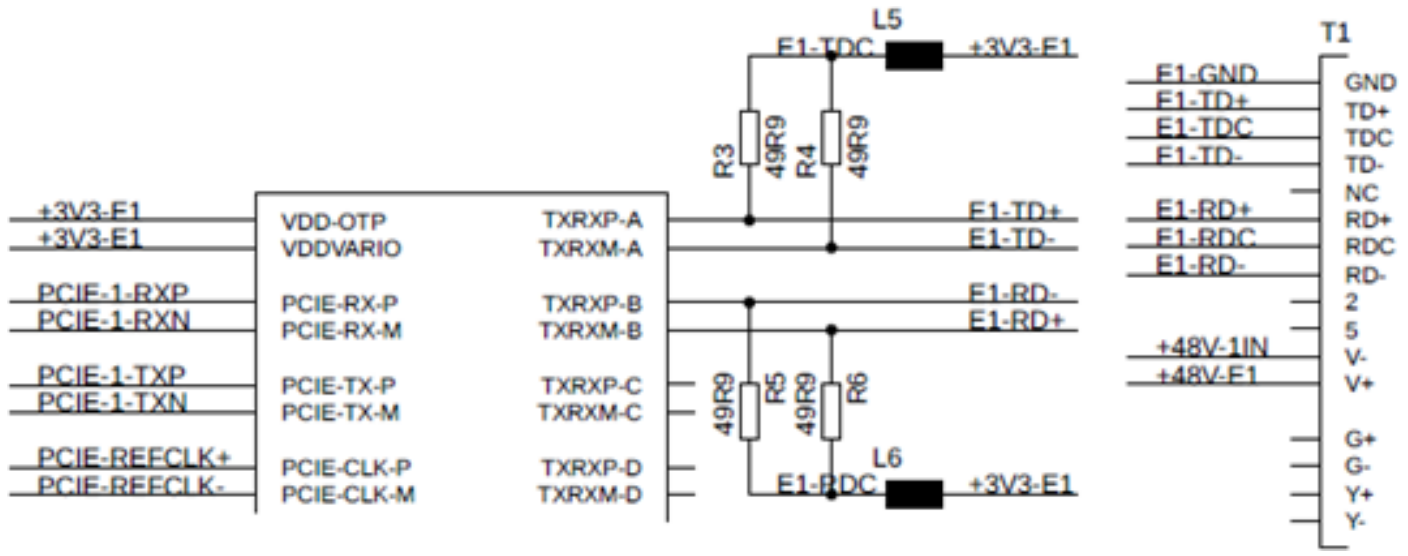

Fig.3. The EMT and the Ethernet PHY interface

The LAN7430 must be powered by several voltages. Due to this problem, several voltage regulators are placed near each chip. There are in total four independent Ethernet circuits on the board with separate regulators for each chip. All Ethernet parts are connected together by the chokes to provide maximal reliability and stability of each line. The schematic part of the power management of each line is shown in the following figure.

The trickiest part of the whole system is the power management of the Power over Ethernet (PoE). As mentioned before, there are three standards for the PoE and each of them has different power demands. According to the requirements, the system should handle the highest standard of the PoE called Hi-PoE and the power system should provide at least $44 \mathrm{~V}$ with a total power of $60 \mathrm{~W}$. The power for the PoE must be distributed to all four parts separately. However, the minimal voltage for the PoE is $44 \mathrm{~V}$ per Ethernet port, and the power source of the $\mathrm{PC}$ has the maximal voltage $12 \mathrm{~V}$. It means that there must be a $48 \mathrm{~V}$ voltage multiplier for each line with enough power. According to this problem, the voltage multiplier from $12 \mathrm{~V}$ to $48 \mathrm{~V}$ is designed for the PoE system and the schematic can be found in the following figure.

This DC/DC converter is connected in the topology of a multiplier and the well-known UC3843 is used as the main control circuit. The drive uses a transformer that must have a conversion ratio of exactly $1: 1$. It is wound with two identical lacquered conductors at the same time on an iron- 
powder toroidal core. The Q4 is a low-voltage N-type MOSFET with the lowest on-state resistance. Q4 and D1 see the sum of the input and output voltages during operation and must be rated for at least $1.25 x$ the maximum considered voltage. The operating frequency of the circuit is about $90-95 \mathrm{kHz}$. The power components and electrolytes need to be adapted to the required parameters.

One of the following requirements of the system is a function that enables or disables the PoE to each port. This is done by the optocoupler which acts as an electronic relay and it also provides the galvanic separation. The second useful function is the measuring of the current consumption by the connected device. This function can detect the overcurrent or the short circuit. Both functions are controlled by the separate microcontroller ATmega2560. [17]

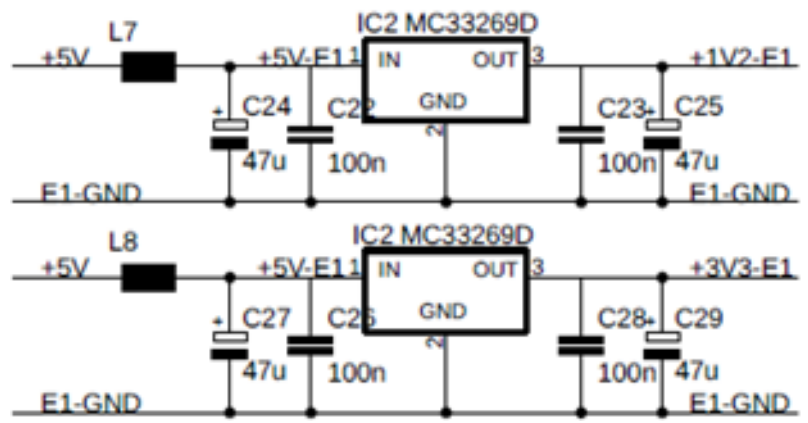

Fig.4. Power supply for each Ethernet part

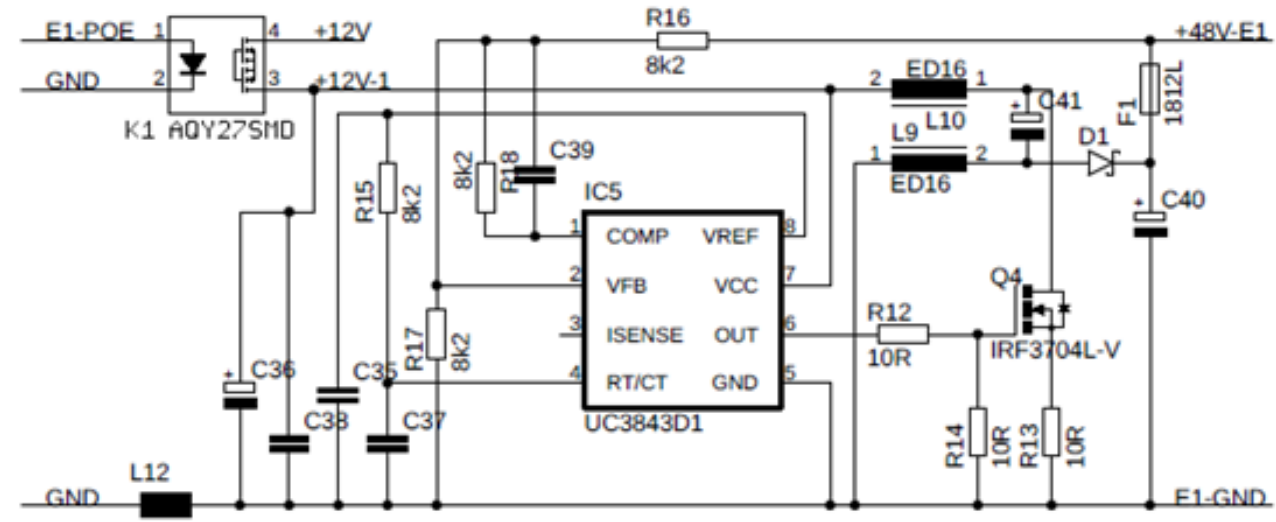

Fig.5. The multiplier for the Power over Ethernet

\section{The Serial AT Attachment}

The most common VSS usually collect video signal from all connected devices and it stores it on the Hard Drive Disc (HDD). This process is done by the Central Processor Unit (CPU) which is usually responsible for the communication between the device and the HDD. However, this communication slows down the CPU which can lead to jamming and lagging the video signal. The design is supported by the pair of the SATA drivers with the data connectors on the board. It means that the video signal can be transmitted through the $\mathrm{PCl}-\mathrm{E}$ without any access to the CPU. Moreover, the HDD is not using the main SATA bus on the mainboard which is convenient. The schematic part of the SATA connection is done by the TUSB9261 and the chip is directly connected to the PCl-E.

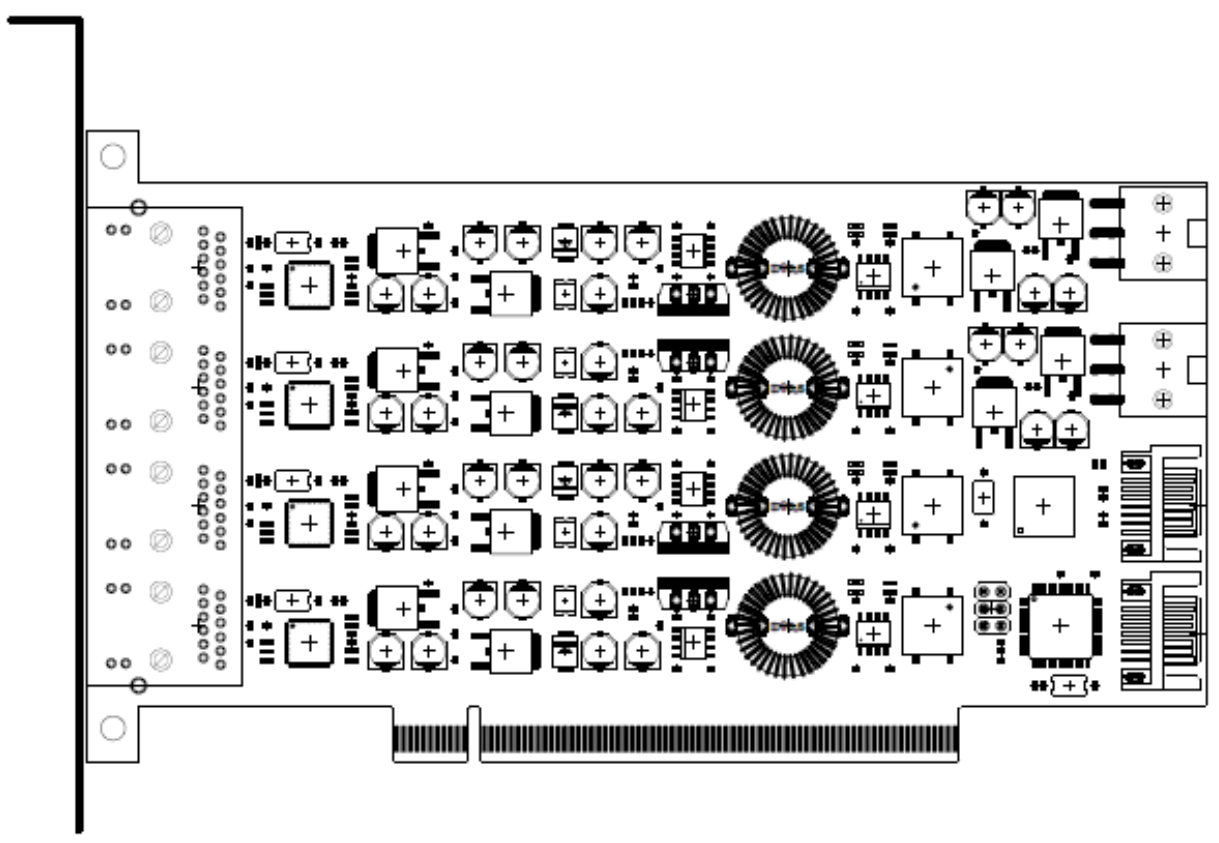

Fig.6. The final design of the PCl-Express card 


\section{The Design of the Ethernet Card Based on the PCl-} Express

All schematics from the previous chapter are placed on the two-sided PCB. As mentioned before, the part for the Ethernet connection is placed on the PCB four times, where each part has separated power by the chokes. It means that each Ethernet chip has its own power management and own PoE management per port which provides a stable and reliable function. The voltage multiplier for the PoE uses a high power MOSFET transistor which produces a lot of heat loss which must be dissipated into the air from the device.

The total power of the passive heat transition is enough for the maximal power of the 70 Watts. The card should be able to provide the PoE function at all Ethernet ports at the same time. It means that the card at full load can consume for all four ports 280 Watts only for the PoE function. Another 35 Watts are consumed by the Ethernet and SATA chips. The board can consume at full load up to 320 Watts in total. According to this problem, the board has two power terminals called 6pin $\mathrm{PCl}-\mathrm{E}$ power connector which can provide the required power. [18]

Next to the power terminal is placed another set of terminals for the SATA cable where can be directly connected the HDD to store a video signal. Each line is controlled by the individual chip called TUSB9261. It means that the HDD used only for the recording the video signal does not occupy the SATA ports on the motherboard. The last important chip on the board is called ATmega2560 which is responsible for the communication between all chips and it is also controlling the PoE management. All chips are connected together using the JTAG common bus. The final board itself has dimensions that fit into the standardization and the system uses the PCl-E 16x connector. This connector provides enough lines for all chips that using the $\mathrm{PCl}-\mathrm{E}$ bus and it also provides the structural stability to the board in the PC case.

\section{Results and Discussion}

The board is connected to the computer by the PCl-E $16 \mathrm{x}$ which has sixteen independent so-called lanes where each lane is connected to the one device. In this scenario, two lanes are connected to the SATA driver where the HDD or SSD disc can be connected and four lanes are connected to the Ethernet controller LAN7430. It means that the current design can handle up to four independent IP cameras which are requiring the PoE standard using six lanes out of the sixteen. However, this number of the Ethernet connectors can be very easily extended up to fourteen connectors using the expanding board placed on the top of the existing card. This comes with the more power consumption up to $980 \mathrm{~W}$ in full load on the board.

As mentioned before, the PCI-E 16x using 16 lanes from the chipset situated physically on the motherboard. Each version of the chipset has a different maximal amount of the lanes which can be used for the PCI-E connectors. The ideal chipset currently available on the market is from the AMD company called AMD X399 which has 66 PCl-E lanes. It means that up to four independent designed card can be connected with a maximal number of the Ethernet ports can be connected to the motherboard using the chipset AMD X399. The user must choose the motherboard with the chipset AMD X399 and it also needs to have all four PCI-E connectors physically placed of the board. With this setup, the maximal number of independently connected IP cameras is 56 to one computer.

The VSS is well known for its ability to streaming a big amount of data through the network. It is obvious, that the whole system where VSS would be deployed should fulfill expected requirements for the continuous processing of video sequences. Moreover, with the introduction of new types of cameras, where multiple image sensors are connected via a single Ethernet connection. This category is represented mainly by multisensory cameras, which are trending nowadays within the VSS industry. The expected bandwidth consumption is far behind of Ethernet interface provided by the designed network card.

The last limitation can be the insufficient speed of the connected HDDs using the SATA interface. This limitation can be solved by the faster interface called the M. 2 which is also using the $\mathrm{PCl}-\mathrm{E}$ lane with the greater baud rate.

\section{Conclusion}

The main goal of this article was to design the card for VSS application which can be connected to the PC using the $\mathrm{PCl}-\mathrm{E}$ bus. The final design has four separate Ethernet ports and each port is supported by the $\mathrm{PoE}, \mathrm{PoE}+$ or $\mathrm{Hi}-$ PoE according to the standardization. All ports using the LAN7430 chip which communicates with the computer via the $\mathrm{PCl}-\mathrm{E}$ lanes and each chip has independent power management. The power management can handle up to 70 Watts per one Ethernet port and each line has its own power consumption measurement which can be used for the management and other evaluations. The card has two separate SATA terminal for two independent HDDs. The incoming signal can be directly saved on the HDD using the $\mathrm{PCl}-\mathrm{E}$ bus which does not require any CPU power. The card must be powered by at least two 6pin PCl-E power connectors which can handle up to 320 Watts.

All chips come from the manufacturer with the program which can be upgraded and the driver is automatically installed by the operating system. The chip called ATmega2560 is responsible for the managing, upgrading, $\mathrm{PoE}$ enabling and measuring can be programmed and controlled from the operating system by application interface. The design can be extended up to fourteen independent Ethernet ports where the IP cameras can be connected.

Acknowledgments: This work was supported by the Ministry of Education, Youth and Sports of the Czech Republic within the National Sustainability Program Project No. LO1303 (MSMT-7778/2014) and also by the European Regional Development Fund under the project CEBIA-Tech ED2.1.00/03.0089 and by the Internal Grant Agency of Tomas Bata University under the project No. IGA/CebiaTech/2020/003.

\section{Authors}

Jiri Sevcik Tomas Bata University in Zlin, Faculty of Applied Informatics, Nad Stranemi 4511, 76005 Zlin, Czech Republic (email: jsevcik@utb.cz).

Vaclav Mach, Tomas Bata University in Zlin, Faculty of Applied Informatics, Nad Stranemi 4511, 76005 Zlin, Czech Republic (email:v2mach@utb.cz).

Milan Adamek, Tomas Bata University in Zlin, Faculty of Applied Informatics, Nad Stranemi 4511, 76005 Zlin, Czech Republic (email: adamek@utb.cz).

Jan Valouch, Tomas Bata University in Zlin, Faculty of Applied Informatics, Nad Stranemi 4511, 76005 Zlin, Czech Republic (email: valouch@utb.cz).

Karla Barcova, VSB - Technical university of Ostrava, Faculty of Safety Engineering, Lumirova 630/13, 70030 Ostrava - Vyskovice, Czech Republic (e-mail: karla.barcova@vsb.cz).

\section{REFERENCES}

[1] Landa J., Jun Ch., Jun M., Implementation of a Remote Real-Time Surveillance Security System for Intruder Detection, 9th International Conference on Measuring Technology and Mechatronics Automation (ICMTMA), (2017) 
[2] Valouch J., The Proposal of Methodology for Evaluating the Effectiveness of Alarm Systems, Applied Mechanics and Materials, (2015), 183-88

[3] Ljubymenko K., Adámek M., Security personnel of new generation," Proceedings - International Carnahan Conference on Security Technology, Montreal: Institute of Electrical and Electronics Engineers, (2017)

[4] Li W., Gao Y., Design of Network Camera Based on ONVIF in the Dark Environment. International Conference on Sensor Networks and Signal Processing (SNSP), (2018), 84-87

[5] Hart J., Hartova V., Testing of combined space detectors in intrusion and hold-up alarm systems, Engineering for Rural Development, (2018), 905-909

[6] Blahová M., Hromada M., The Soft Targets in the Czech Republic and Their Security, Trilobit, 10(2019)

[7] Shim Ch., Shinde R., Choi M., Compatibility Enhancement and Performance Measurement for Socket Interface with PCIE Interconnections, Human-Centric Computing and Information Sciences, 9(2019)

[8] Neugebauer R., Understanding PCle performance for end host networking. Proceedings of the 2018 Conference of the ACM Special Interest Group on Data Communication, (2018), 327-34

[9] Gabrielli A., Alfonsi F., Balbi G., Damen G., Falchieri D., Giangiacomi N., Travaglini R., A MultiChannel Pci Express Readout Board for Fast Readout of Large Pixel Detectors. Nuclear Instruments and Methods in Physics Research Section: Accelerators, Spectrometers, Detectors and Associated Equipment, (2018), 279-281
[10]Gao Y., Ma H., Liu W., Yu S., Cost Optimal Resource Provisioning for Live Video Forwarding Across Video Data Centers. Springer International Publishing, (2016), 27-38

[11]Ravindran M., Cabled PCI Express-A Standard High-Speed Insterument Interconnect. IEEE Autotestcon, (2007), 410-417

[12] Du T., Jia O., Design of Universal PCle Interface Module Based on Vs. IOP Conference Series: Materials Science and Engineering, (2018), 449

[13]De D., Martin I., Roman S., Montero C., Conde C., Cabello E., Scalable and flexible wireless distributed architecture for intelligent video surveillance systems, Multimedia Tools and Applications, 78(2019),17437-17459

[14]Jiang L., Implementation of a Remote Real-Time Surveillance Security System for Intruder Detection, 9th International Conference on Measuring Technology and Mechatronics Automation, (2017)

[15]Liu X., Ma H., Li S., PVSS: A Progressive Vehicle Search System for Video Surveillance Networks. Journal of Computer Science and Technology, 34(2019), 634-644

[16]Ahmed K., Hasaneen E., Orabi M., Power management system for Ethernet-based IoT devices, Ain Shams Engineering Journal, 9(2018), 3033-3043

[17]Pospisilik M., Remote controlled gate controller using a GSM network and Arduino platform, MATEC Web of Conferences, (2016), 02036

[18]Xiao Z., An Efficient Power Over Ethernet (PoE) Interface with Current-Balancing and Hot-Swapping Control, IEEE Transactions on Industrial Electronics, 65(2018), 2496-2506 